\title{
The Methods and Use of Questionnaires for the Diagnosis of Dental Phobia by Japanese Dental Practitioners Specializing in Special Needs Dentistry and Dental Anesthesiology: A Cross-Sectional Study
}

\section{Mika Ogawa}

Fukuoka Dental University

Terumi Ayuse ( $\nabla$ ttagawa@nagasaki-u.ac.jp )

Nagasaki University Hospital

Toshiaki Fujisawa

Hokkaido University

Shuntaro Sato

Nagasaki University Hospital

Takao Ayuse

Nagasaki University Graduate School of Biomedical Science

\section{Research Article}

Keywords: Dental phobia, questionnaire, special needs dentistry, dental anesthesiology, and dental practitioner

Posted Date: September 28th, 2021

DOl: https://doi.org/10.21203/rs.3.rs-913535/v1

License: (c) (1) This work is licensed under a Creative Commons Attribution 4.0 International License.

Read Full License

Version of Record: A version of this preprint was published at BMC Oral Health on February 11th, 2022. See the published version at https://doi.org/10.1186/s12903-022-02071-y. 


\section{Abstract \\ Background}

Dental phobia is covered by medical insurance; however, the diagnostic methods are not standardized in Japan. Therefore, the aim of this study was to investigate the methods and use of questionnaires for the diagnosis of dental phobia by Japanese dental practitioners specializing in special needs dentistry and dental anesthesiology.

\section{Methods}

We conducted an online survey to obtain information from the members of the Japanese Society for Disability and Oral Health (JSDH, $n=5134$ ) and the Japanese Dental Society of Anesthesiology (JDSA, $n$ = 2759). Response items included gender, qualification, affiliation type, methods of diagnosis and management of dental phobia, use of questionnaire, need for new evaluation methods for the diagnosis of dental phobia, and others. The chi-squared test was used to compare answers between the three groups (JSDH only, JDSA only, and both). Multiple logistic regression analysis was conducted to identify factors associated with the use of an assessment questionnaire.

\section{Results}

Data were obtained from 614 practitioners (only JSDH: $n=329$, only JDSA: $n=195$, both JSDH and JDSA: $n=90$, response rate: $7.8 \%$ [614/7,893], men: $n=364$ [58.5\%]). Only $9.7 \%$ practitioners used questionnaires to quantify the level of dental anxiety. The members of both JSDH and JDSA used questionnaires more frequently than members only of the JSDH ( $19 \%$ and $7.1 \%$, respectively; Bonferroni corrected $p$ < 0.01). Most practitioners (89.1\%) diagnosed dental phobia based on patient complaints of fear of treatment. Further, majority of the participants (73.3\%) felt the need for a new diagnostic method for "dental phobia". Multiple logistic regression analysis showed that membership of the JSDH only was negatively related (odds ratio $[\mathrm{OR}]=0.32,95 \%$ confidence interval $[\mathrm{Cl}]: 0.15-0.68$ ), and use of behavioral therapy was positively related $(\mathrm{OR}=2.51,95 \% \mathrm{Cl}: 1.27-5.20)$ to the use of a questionnaire.

\section{Conclusions}

The results of this study showed that the use of questionnaires was very low, patients' subjective opinions were commonly used to diagnose dental phobia, and a new diagnostic criterion was needed among practitioners. Therefore, it is important to establish standardized methods for diagnosing dental phobia in Japan.

\section{Background}


Dental phobia is recognized as extremely high anxiety for dental treatment. In such cases, it is difficult to perform dental treatments using routine methods $(1,2)$. Therefore, dental treatments for patients with dental phobia can be performed using cognitive behavioral therapy or under sedation $(2,3)$. "Dental phobia" is covered by health insurance in Japan.

In Japan and other countries, patients with mild dental phobia can be treated in routine outpatient dental clinics, while those with moderate-to-severe dental phobia are treated at high-level hospitals with a provision of special care dentistry using behavioral therapy, sedation, or general anesthesia $(2,4,5)$. Higher dental institutions are associated with experienced dentists, who are often the members of the Japanese Society for Disability and Oral Health (JSDH) and the Japanese Dental Society of Anesthesiology (JDSA). A clear definition or diagnostic criterion for dental phobia has not been established; therefore, the diagnosis of dental phobia depends on the experience of dentists in Japan.

According to the Diagnostic and Statistical Manual of Mental Disorders, Fifth Edition (DSM-5), dental phobia is a specific type of phobia (localized phobia) (6). Specific phobia is a condition in which a person feels fear or anxiety about a specific situation or subject. Diagnosis is based on interviews or selfadministered questionnaires formulated according to the DSM- 5 criteria. The incidence of dental phobia based on the DSM classification is 2.1\% (Sweden) (7), 3.1\% (USA) (8), and 3.7\% (Netherlands) (9).

In contrast, another concept of dental phobia has been proposed. In other countries, the concept of dental fear and anxiety is a continuum, rather than the dichotomy of scary/not scary. Multiple psychological scales have been developed to quantify the level of dental anxiety or fear $(1,2,3)$. Quantification is essential for determining the methods to deal with dental fear or anxiety $(10,11)$. Therefore, multiple psychological scales with established reliability and validity have been developed and used worldwide (3). For example, the Modified Dental Anxiety Scale (MDAS) is a five-item questionnaire that quantifies the degree of anxiety in five dental situations (12). The total score ranges from 5 to 25 . An MDAS score of 19 or higher indicates a high level of dental anxiety and specific phobia (13). The prevalence of high dental fear (MDAS score $\geq 19$ ) was $11.3 \%$ in Japan (14), 11.6\% in the UK (12), 10.9\% in Spain (15), and $8.7 \%$ in China (16). Dental fear/dental anxiety is also evaluated using single-question and non-MDAS questionnaires, such as Dental Anxiety Scale (17) and Dental Fear Survey (18), with high dental fear reported with an incidence of 4-30\% (19). Most recently, the global estimated prevalence of dental fear and anxiety (DFA), high DFA, and severe DFA in adults has been reported as $15.3 \%$ (95\% confidence interval [Cl], 10.2-21.2), $12.4 \%(95 \% \mathrm{Cl}, 9.5-15.6)$, and $3.3 \%(95 \% \mathrm{Cl}, 0.9-7.1)$, respectively, based on 31 studies included in a systemic meta-analysis (20).

In a survey of 400 adults in Japan, $11.3 \%$ exhibited high dental anxiety based on MDAS scores; however, $44.0 \%$ answered that they "want to receive a little" or "very much want to receive" dental treatment under intravenous sedation (21). The prevalence of dental phobia according to the DSM classification has not been investigated in Japan, but it is estimated to be approximately $3-5 \%$ based on previous studies conducted overseas $(7,8,9)$. 
The term dental phobia is commonly used among general dentists and even patients in Japan; however, the incidence of high dental anxiety based on responses to questionnaires and of dental phobia based on the DSM classification and demands for intravenous sedation do not seem to correspond. Therefore, the aim of this study was to investigate the methods used to diagnose "dental phobia" by Japanese practitioners who specialize in special needs dentistry and/or anesthesiology.

\section{Methods}

Members of the JSDH (total number of members: 5,134 ) and the JDSA (total number of members: 2,759 ) were targeted for this study. All methods were carried out in accordance with the Declaration of Helsinki. All experimental protocols including the method of obtaining consent from the participants were approved by the respective boards of both academic societies (No. 1920-7 from the JDSA and No. 20029 from JSDH). We conducted an online questionnaire survey (total number of requests: 7,893) using Google Forms (California, Google LLC). The web address for the questionnaire survey was sent to all members via e-mail newsletters of both academic societies. Participation in the survey was totally voluntary and anonymous. The aim and other details of the study were explained in the first screen. Clicking on the button located at bottom of the first screen was taken as informed consent. Any anonymous responses between August 7, 2020 and August 22, 2020 were recorded on the internet form.

The questionnaire included the following items:

1) Gender (male, female)

2) Qualification (specialist, certified doctor, certified dental hygienist, other)

3) Affiliation type (individual clinic, university hospital, regional clinic, hospital dentistry)

4) Method for management (behavioral therapy, intravenous sedation, general anesthesia, conscious sedation, oral sedation, other)

5) Criteria for diagnosing dental phobia in new patients (patient complaints of anxiety, experience of feeling unwell during treatment, difficulty in keeping the patient's mouth open during treatment, body movement during treatment, cancelation of dental reception, other).

6) The use of a questionnaire or criteria to diagnose dental phobia (Yes/No)

7) Dental anxiety assessment indices used (seven specific questionnaires and original evaluation criteria)

8) Need for new evaluation methods for the diagnosis of dental phobia (Very needed, a little needed,either, not needed a little, no need at all) and

9) Percentage of patients with dental phobia treated every week.

\section{Statistical analysis}

Characteristics and questionnaires' answers are summarized in counts and percentages. The chi-squared test or Fisher's exact test were used to compare answers between the three groups (JSDH only, JDSA only, and both of JSDH and JDSA). Then, the comparison of the two groups was tested in the same test, and the $\mathrm{P}$ value was corrected for Bonferroni correction. Multiple logistic regression analysis was conducted 
to identify factors associated with the use of a dental anxiety assessment questionnaire and estimated Odds ratios (ORs), $95 \%$ confidence intervals (95\% Cls), and p-values. This model included gender, membership, facility type, and five types of management as independent factor. All tests were conducted at a significance level of 0.05. All statistical analyses were performed with $R$ version 4.0.0 (R Foundation for Statistical Computing, Vienna, Austria).

\section{Results}

A total of $7.8 \%(622 / 7,893)$ participants responded to the survey. Eight responses had missing data; therefore, 614 responses were analyzed. Fifty-eight participants were male (356/614). Table 1 shows the qualifications of the participants. Thirteen percent members of the JSDH were specialists (53/419), whereas $38.2 \%$ members of JDSA were specialists (109/285). Almost 10\% participants (66/614) calculated that the proportion of patients with dental phobia treated every working week was $25 \%$.

Table 1

Qualification of the participants

\begin{tabular}{|llc|}
\hline & JSDH n (\%) & JDSA n (\%) \\
\hline Specialist & $53(12.6)$ & $109(38.2)$ \\
\hline Certified doctors & $192(45.8)$ & $132(46.3)$ \\
\hline Certified dental hygienist & $33(7.9)$ & $7(2.5)$ \\
\hline Others & $141(33.7)$ & $37(13.0)$ \\
\hline Total & $419(100)$ & $285(100)$ \\
\hline $\begin{array}{l}\text { JSDH = Japanese Society for Disability and Oral Health, JDSA = Japanese Dental Society of } \\
\text { Anesthesiology }\end{array}$ & \\
\hline
\end{tabular}

The common answers and differences among members are shown in Table 2. The percentages of affiliated facility type, use of questionnaires, practical diagnostic criteria, need for new evaluation methods, and methods of management were significantly different between the groups. Approximately one-third of the respondents worked at an individual clinic, and one-third worked at a university hospital. Behavioral therapy was significantly used more frequently among members of the JSDH only (JSDH group, 264/329 [80\%]) than among members of the JDSA only (JDSA group, 66/195 [34\%], corrected $p<$ $0.01)$. Intravenous sedation was significantly used more commonly in the JDSA group than in the JSDH group (170/195 [87\%] and 162/329 [49\%] respectively; corrected $p<0.01)$. 
Table 2

The difference on the answer between memberships

\begin{tabular}{|c|c|c|c|c|c|}
\hline & Overall & $\begin{array}{l}\text { JSDH } \\
\text { only }\end{array}$ & $\begin{array}{l}\text { JDSA } \\
\text { only }\end{array}$ & $\begin{array}{l}\text { Both of JSDH } \\
\text { and JDSA }\end{array}$ & $\begin{array}{l}\text { p- } \\
\text { value* }\end{array}$ \\
\hline & $\begin{array}{l}N= \\
614\end{array}$ & $\begin{array}{l}N= \\
329\end{array}$ & $\begin{array}{l}N= \\
195\end{array}$ & $N=90$ & \\
\hline & $\mathrm{n}(\%)$ & $\mathrm{n}(\%)$ & $\mathrm{n}(\%)$ & $n(\%)$ & \\
\hline Gender & & & & & 0.074 \\
\hline Male & $\begin{array}{l}356 \\
(58)\end{array}$ & $\begin{array}{l}197 \\
(61)\end{array}$ & $\begin{array}{l}101 \\
(52)\end{array}$ & $58(64)$ & \\
\hline Female & $\begin{array}{l}253 \\
(42)\end{array}$ & $\begin{array}{l}128 \\
(39)\end{array}$ & $\begin{array}{l}93 \\
(48)\end{array}$ & $32(36)$ & \\
\hline (Missing) & 5 & 4 & 1 & 0 & \\
\hline Affiliation type & & & & & 0.041 \\
\hline Individual clinic & $\begin{array}{l}223 \\
(36)\end{array}$ & $\begin{array}{l}122 \\
(37)\end{array}$ & $\begin{array}{l}73 \\
(37)\end{array}$ & $28(31)$ & \\
\hline University hospital & $\begin{array}{l}194 \\
(32)\end{array}$ & $\begin{array}{l}88 \\
(27)\end{array}$ & $\begin{array}{l}71 \\
(36)\end{array}$ & $35(39)$ & \\
\hline Regional clinic & $\begin{array}{l}99 \\
(16)\end{array}$ & $\begin{array}{l}64 \\
(19)\end{array}$ & $\begin{array}{l}20 \\
(10)\end{array}$ & $15(17)$ & \\
\hline Hospital dentistry & $\begin{array}{l}98 \\
(16)\end{array}$ & $\begin{array}{l}55 \\
(17)\end{array}$ & $\begin{array}{l}31 \\
(16)\end{array}$ & $12(13)$ & \\
\hline The use of a questionnaire & & & & & 0.004 \\
\hline Yes & $\begin{array}{l}60 \\
(9.8)\end{array}$ & $\begin{array}{l}23 \\
(7.1)\end{array}$ & $\begin{array}{l}20 \\
(10)\end{array}$ & $17(19)$ & \\
\hline No & $\begin{array}{l}550 \\
(90)\end{array}$ & $\begin{array}{l}302 \\
(93)\end{array}$ & $\begin{array}{l}175 \\
(90)\end{array}$ & $73(81)$ & \\
\hline (Missing) & 4 & 4 & 0 & 0 & \\
\hline \multicolumn{6}{|l|}{$\begin{array}{l}\text { Criteria for diagnosing dental phobia in } \\
\text { new patients }\end{array}$} \\
\hline Patient's complaining of anxiety & $\begin{array}{l}546 \\
(89)\end{array}$ & $\begin{array}{l}287 \\
(87)\end{array}$ & $\begin{array}{l}177 \\
(91)\end{array}$ & $82(91)$ & 0.400 \\
\hline $\begin{array}{l}\text { Experience of feeling unwell during } \\
\text { treatment }\end{array}$ & $\begin{array}{l}397 \\
(65)\end{array}$ & $\begin{array}{l}206 \\
(63)\end{array}$ & $\begin{array}{l}131 \\
(67)\end{array}$ & $60(67)$ & 0.500 \\
\hline $\begin{array}{l}\text { Difficulty in keeping the patient's mouth } \\
\text { open during treatment }\end{array}$ & $\begin{array}{l}174 \\
(28)\end{array}$ & $\begin{array}{l}101 \\
(31)\end{array}$ & $\begin{array}{l}38 \\
(19)\end{array}$ & $35(39)$ & 0.001 \\
\hline
\end{tabular}




\begin{tabular}{|c|c|c|c|c|c|}
\hline & Overall & $\begin{array}{l}\text { JSDH } \\
\text { only }\end{array}$ & $\begin{array}{l}\text { JDSA } \\
\text { only }\end{array}$ & $\begin{array}{l}\text { Both of JSDH } \\
\text { and JDSA }\end{array}$ & $\begin{array}{l}\text { p- } \\
\text { value* }\end{array}$ \\
\hline Body movement during treatment & $\begin{array}{l}391 \\
(64)\end{array}$ & $\begin{array}{l}229 \\
(70)\end{array}$ & $\begin{array}{l}108 \\
(55)\end{array}$ & $54(60)$ & 0.003 \\
\hline Cancellation of dental reception & $\begin{array}{l}149 \\
(24)\end{array}$ & $\begin{array}{l}80 \\
(24)\end{array}$ & $\begin{array}{l}46 \\
(24)\end{array}$ & $23(26)$ & $>0.9$ \\
\hline Need for a new evaluation method & & & & & 0.004 \\
\hline Very needed/ a little needed & $\begin{array}{l}446 \\
(73)\end{array}$ & $\begin{array}{l}257 \\
(78)\end{array}$ & $\begin{array}{l}127 \\
(65)\end{array}$ & $62(69)$ & \\
\hline Either/ not needed a little/ no need at all & $\begin{array}{l}168 \\
(27)\end{array}$ & $\begin{array}{l}72 \\
(22)\end{array}$ & $\begin{array}{l}68 \\
(35)\end{array}$ & $28(31)$ & \\
\hline \multicolumn{6}{|l|}{ Method for management } \\
\hline Behavioral therapy & $\begin{array}{l}384 \\
(63)\end{array}$ & $\begin{array}{l}264 \\
(80)\end{array}$ & $\begin{array}{l}66 \\
(34)\end{array}$ & $54(60)$ & $<.001$ \\
\hline Intravenous sedation & $\begin{array}{l}412 \\
(67)\end{array}$ & $\begin{array}{l}162 \\
(49)\end{array}$ & $\begin{array}{l}170 \\
(87)\end{array}$ & $80(89)$ & $<.001$ \\
\hline General anesthesia & $\begin{array}{l}283 \\
(46\end{array}$ & $\begin{array}{l}125 \\
(38)\end{array}$ & $\begin{array}{l}98 \\
(50)\end{array}$ & $60(67)$ & $<.001$ \\
\hline Laughing inhalation sedation & $\begin{array}{l}296 \\
(48)\end{array}$ & $\begin{array}{l}165 \\
(50)\end{array}$ & $\begin{array}{l}80 \\
(41)\end{array}$ & $51(57)$ & 0.028 \\
\hline Oral sedation & $\begin{array}{l}55 \\
(9.0)\end{array}$ & $\begin{array}{l}17 \\
(5.2)\end{array}$ & $\begin{array}{l}23 \\
(12)\end{array}$ & $15(17)$ & $\begin{array}{l}<.001 \\
0.0\end{array}$ \\
\hline Others & $\begin{array}{l}25 \\
(4.1)\end{array}$ & $\begin{array}{l}17 \\
(5.2)\end{array}$ & $\begin{array}{l}6 \\
(3.1)\end{array}$ & $2(2.2)$ & 0.400 \\
\hline (Missing) & 1 & 0 & 1 & 0 & \\
\hline \multicolumn{6}{|l|}{ *Pearson's Chi-squared test } \\
\hline $\begin{array}{l}\text { JSDH = Japanese Society for Disability a } \\
\text { Anesthesiology }\end{array}$ & al Heal & JDSA $=$ & apane & ental Society of & \\
\hline
\end{tabular}

Only 9.8\% (60/614) participants used a questionnaire to diagnose dental phobia. The members of both JSDH and JDSA used questionnaires more frequently than members only of the JSDH (17/90 [19\%] and $23 / 329$ [7.1\%] respectively; corrected $p<0.01)$. Eighty-nine percent $(546 / 614)$ participants diagnosed dental phobia based on patient complaints of anxiety, and $65 \%(393 / 614)$ by experience of feeling unwell during treatment. Difficulty in keeping the patient's mouth open during treatment was significantly used more frequently as a diagnostic criterion among JSDH members than among JDSA members (101/329 [31\%] and 38/195 [19\%], respectively; corrected $p=0.02$ ). Body movement during treatment was also 
significantly used more common as a diagnostic criterion among JSDH members than among JDSA members $(229 / 329$ [70\%] and 108/195 [55\%], respectively; corrected $p<0.01)$.

Table 3 shows the various dental anxiety assessment questionnaires used by practitioners. Sixty-four percent of the respondents (39/60) who used questionnaires used original evaluation criteria for the diagnosis of dental anxiety. Seventy-three percent respondents (446/612) felt that an established diagnostic method for dental phobia was needed (Table 2). More number of members of the JSDH felt the need for new diagnostic methods than of those of the JDSA (257/329 [78\%] and 127/195 [65\%], respectively; corrected $\mathrm{p}<0.01)$.

Table 3

Questionnaires used by respondents

\begin{tabular}{|ll|}
\hline Questionnaires & $\mathrm{n}(\%)$ \\
\hline Modified Dental Anxiety Scale & $9(15.1)$ \\
\hline Dental Fear Survey & $6(10.3)$ \\
\hline The short version of the Dental Anxiety Inventory & $2(2.4)$ \\
\hline Dental Subscale of Children's Fear Survey Schedule & $1(1.6)$ \\
\hline Visual Analog Scale & $12(19.8)$ \\
\hline State-Trait Anxiety Inventory & $4(6.3)$ \\
\hline State-Trait Anxiety Inventory for Children & $1(1.6)$ \\
\hline Original evaluation criteria & $39(64.3)$ \\
\hline respondents were able to choose more than one & \\
\hline
\end{tabular}

\section{Multiple Regression Analysis}

Table 4 showed the associations between the use of the dental anxiety assessment questionnaires and participants' characteristics. The factors that found a statistically significant association with the use of dental anxiety assessment questionnaires were membership of the JSDH (OR $=0.32,95 \% \mathrm{Cl}$ : $0.15-0.68$, $p=0.003)$ and use of behavioral therapy $(O R=2.51,95 \% \mathrm{Cl}: 1.27-5.20, p=0.01)$. 
Table 4

Results of a logistic regression analysis for the usage of questionnaire to diagnose dental phobia

\begin{tabular}{|llll|}
\hline Variables & OR & $95 \%$ Cl & P value \\
\hline Gender & \multicolumn{3}{l}{} \\
\hline Female & - & - & - \\
\hline Male & 1.66 & $0.93,3.07$ & 0.095 \\
\hline Memberships & & & \\
\hline JSDH only/ both & - & - & - \\
\hline JDSA only & 0.67 & $0.32,1.42$ & 0.29 \\
\hline JDSA only/ both & - & - & - \\
\hline JSDH only & 0.32 & $0.15,0.68$ & 0.003 \\
\hline Affiliated facility type & 1.29 & $0.65,2.62$ & 0.47 \\
\hline Behavioral therapy & 2.51 & $1.27,5.20$ & 0.01 \\
\hline Intravenous sedation & 1.39 & $0.65,3.08$ & 0.41 \\
\hline General anesthesia & 1.16 & $0.60,2.30$ & 0.66 \\
\hline Laughing inhalation sedation & 0.91 & $0.50,1.65$ & 0.76 \\
\hline Oral sedation & 0.87 & $0.33,2.05$ & 0.77 \\
\hline $\begin{array}{l}\text { OR = Odds Ratio, Cl = Confidence Interval, JSDH = Japanese Society for Disability and Oral Health, } \\
\text { JDSA = Japanese Dental Society of Anesthesiology }\end{array}$ & & \\
\hline
\end{tabular}

\section{Discussion}

This study investigated the methods of diagnosis of dental phobia using an online survey among Japanese dental practitioners who specialized in special needs dentistry and dental anesthesiology. The results showed that the use of questionnaires was very low, patients' subjective opinions were mostly used to diagnose dental phobia, and a new diagnostic criterion was needed among practitioners.

Only $9.7 \%$ of the practitioners included in the analysis who specialized in special needs dentistry and dental anesthesiology used questionnaires to quantify the level of dental anxiety. These findings can be compared with those of UK- and Australia-based studies. Among practitioners interested in behavioral sciences in the UK, $20 \%$ used questionnaires (22) and $3.4 \%$ of general dentists in Australia used published scales (23). The difference between the results of our study and these studies could be explained by the difference in the composition of the study population. Nonetheless, use of questionnaires for the diagnosis of dental anxiety was uncommon among dentists. 
The results of this study showed that membership of the JSDH only was negatively related to the use of a questionnaire. This could be because the ratio of certified doctors or specialists was lower among the members of the JSDH than among those of the JDSA. In contrast, these results also revealed that the use of behavioral therapy was positively related to the use of a questionnaire. Behavioral therapy is a psychological approach for the management of dental phobia (2); therefore, analysis of dental anxiety using published tools would be common among dentists who use behavioral therapy.

The previous study has reported that female dentists and dentists who used the sedation method tend to use questionnaires more frequently (22). However, these tendencies were not observed in our study. Further research with different samples is required.

In this study, we observed that almost $90 \%$ participants diagnosed dental phobia based on patient complaints of fear of dental treatment; this result is similar to that of a previous study conducted in Australia, which showed that almost one-half of dentists directly asked their patients about dental anxiety (23). Several standardized methods for the objective and quantitative evaluation of dental phobia are clinically applied; however, dentists diagnose dental phobia or a high level dental anxiety based on subjective and original methods.

Our study showed that $64 \%$ respondents who use a questionnaire diagnosed dental anxiety based on original evaluation methods. The validity and reliability of unpublished scales is often not analyzed; therefore, such scales are rarely used in research to provide evidence for dental phobia.

Our study showed that $73.3 \%$ participants felt the need for a new evaluation method for "dental phobia. We found a difference between the views of the members of the two societies; members of the JSDH responded "considerable need or limited need" (79\%) more frequently than those of the JDSA (65\%). This difference may be due to the differences in their roles. The members of the JDSA mainly provide general management using sedation or general anesthesia, while the members of the JSDH mainly provide dental treatment using behavioral therapy, such as systematic desensitization. To distinguish between patients who can undergo dental treatment under psychological approaches and patients who need pharmacological approaches, the members of the JSDH more strongly need a new diagnostic method than the members of the JDSA.

The results of this study showed that behavioral therapy, intravenous sedation, general anesthesia, and conscious sedation were commonly used by participants of our study. These methods can be used for dental patients covered by national health insurance in Japan; however, the most effective management method is not known. Behavioral treatment for dental phobia in Sweden is provided by psychologists and dentists with the national health insurance, and it has shown a positive effect over ten years (24). To establish guidelines for the diagnosis and management of dental phobia, randomized controlled trials and cohort studies using standardized evaluation questionnaires through extensive epidemiological surveys are warranted in Japan. 
The main limitation of this study is the low response proportion (7.8\%); therefore, our results may not be generalized to all members of the JDSA and JSDH. It is possible that the members who participated in the study were more likely to have an interest in dental phobia than those who did not participate. The target population may have used fewer questionnaires and have a lesser need for a new diagnostic method for dental phobia. However, this is the first study to assess the methods of diagnosis for dental phobia used by dentists who specialize in special needs dentistry and dental anesthesiology.

\section{Conclusions}

In our study population, the use of questionnaires was very low, patients' subjective opinions were commonly used to diagnose dental phobia, and new diagnostic criteria were needed among the practitioners. Japanese dentists need to establish a standard method in clinical settings for the diagnosis of dental phobia.

\section{Abbreviations}

Japanese Society for Disability and Oral Health; JSDH

Japanese Dental Society of Anesthesiology; JDSA

\section{Declarations}

\section{Ethics approval and consent to participate}

The research project was approved by the respective Research Ethics Committees (No. 1920-7 from the Japanese Dental Society of Anesthesiology and No. 20029 from the Japanese Society for Disability and Oral Health). The study was carried out in accordance with the Declaration of Helsinki. Participation in the study was voluntary and anonymous. Participating members gave their informed consent by voluntarily responding to the survey.

\section{Consent for publication}

Not applicable.

\section{Availability of data and materials}

The datasets used and/or analyzed during the current study are available from the corresponding author on reasonable request.

\section{Competing interests}

The authors declare that they have no competing interests.

\section{Funding}


This research was conducted by the Japanese Dental Society of Anesthesiology with a research grant from the Japanese Association for Dental Science (Issue number: JDSF-DSP1-2020-111-1, task name: Research on the disease concept of dental phobia).

\section{Authors' contributions}

MG conceptualized, investigated, interpreted the data, prepared the original draft, and wrote the manuscript. TA conceptualized, investigated, and prepared the original draft and wrote the manuscript. TF conceptualized, reviewed, and edited the draft. SS performed the interpretation of the data and statistical analysis. TA arranged the research grant, conceptualized, investigated, interpreted the data, prepared the original draft, and wrote the manuscript. All authors read and approved the final manuscript.

\section{Acknowledgments}

The authors thank Shouji Hironaka, Chairman of the Japanese Society for Disability and Oral Health, and Takehiko lijima, Chairman of the Japanese Dental Society of Anesthesiology, for supporting the dissemination of the survey.

\section{References}

1. McNeil D, Randall C. Dental fear and anxiety associated with oral health care: conceptual and clinical issues. In: Mostofsky DI, Fortune F Behavioral Dentistry. 2nd ed. Ames (IA): Blackwell;2014. p. 89107.

2. Appukuttan DP. Strategies to manage patients with dental anxiety and dental phobia: literature review. Clin Cosmet Investig Dent. 2016;8:35-50.

3. Armfield JM, Heaton LJ. Management of fear and anxiety in the dental clinic: a review. Aust Dent $\mathrm{J}$. 2013;58(4):390-407; quiz 531.

4. Harano N, Sago T, Nunomaki M, Nakatsu Y, Yamaguchi K, Shiiba S, et al. A Study of behavior management for a patient with difficulty in cooperating with dental treatment in our clinic. J Jpn Soc. 2017;38(1):64-8.

5. Amano I, Maehama W, Toshimitsu T, Tasaki S, Ozaki A, Kaji C, et al. A study on the application of intravenous sedation and general anesthesia to patients with special needs. J Jpn Soc. 2017;38(1):85-90.

6. Black DW, Grant JE. DSM-5 guidebook: the essential companion to the diagnostic and statistical manual of mental disorders, fifth edition. 2014.

7. Fredrikson M, Annas P, Fischer H, Wik G. Gender and age differences in the prevalence of specific fears and phobias. Behav Res Ther. 1996;34(1):33-9.

8. Stinson FS, Dawson DA, Patricia Chou S, Smith S, Goldstein RB, June Ruan W, et al. The epidemiology of DSM-IV specific phobia in the USA: results from the National Epidemiologic Survey on Alcohol and Related Conditions. Psychol Med. 2007;37(7):1047-59. 
9. Oosterink FM, de Jongh A, Hoogstraten J. Prevalence of dental fear and phobia relative to other fear and phobia subtypes. Eur J Oral Sci. 2009;117(2):135-43.

10. Dailey YM, Humphris GM, Lennon MA. Reducing patients' state anxiety in general dental practice: a randomized controlled trial. J Dent Res. 2002;81(5):319-22.

11. Hally J, Freeman R, Yuan S, Humphris G. The importance of acknowledgement of emotions in routine patient psychological assessment: The example of the dental setting. Patient Educ Couns. 2017;100(11):2102-5.

12. Humphris GM, Morrison T, Lindsay SJ. The Modified Dental Anxiety Scale: validation and United Kingdom norms. Community Dent Health. 1995;12(3):143-50.

13. King KH, Humphris GM. Evidence to confirm the cut-off for screening dental phobia using the Modified Dental Anxiety Scale.. Soc Sci Dent. 2010;1:21-8.

14. Ogawa M, Sago T, Furukawa H. The Reliability and Validity of the Japanese Version of the Modified Dental Anxiety Scale among Dental Outpatients. ScientificWorldJournal. 2020;2020:8734946.

15. Coolidge T, Hillstead MB, Farjo N, Weinstein P, Coldwell SE. Additional psychometric data for the Spanish Modified Dental Anxiety Scale, and psychometric data for a Spanish version of the Revised Dental Beliefs Survey. BMC Oral Health. 2010;10:12.

16. Yuan S, Freeman R, Lahti S, Lloyd-Williams F, Humphris G. Some psychometric properties of the Chinese version of the Modified Dental Anxiety Scale with cross validation. Health Qual Life Outcomes. 2008;6:22.

17. Corah NL. Development of a dental anxiety scale. J Dent Res. 1969;48(4):596.

18. Kleinknecht RA, Klepac RK, Alexander LD. Origins and characteristics of fear of dentistry. J Am Dent Assoc. 1973;86(4):842-8.

19. Ost L, Skaret E. Cognitive Behavioral Therapy for Dental Phobia and Anxiety. Oxford (UK): WileyBlackwell. 2013.

20. Silveira ER, Cademartori MG, Schuch HS, Armfield JA, Demarco FF. Estimated prevalence of dental fear in adults: A systematic review and meta-analysis. J Dent. 2021;108:103632.

21. Ogawa M, Shiotsugu Y, Kaneko Y, Nishida S, Taniguchi S. Recognition of Dental Anesthesiology in Japan: Use of an Internet Survey to Assess the Current Status of Dental Fear. J Jpn Dent Soc Anesthesiol. 2020;48(2):41-50.

22. Dailey YM, Humphris GM, Lennon MA. The use of dental anxiety questionnaires: a survey of a group of UK dental practitioners. Br Dent J. 2001;190(8):450-3.

23. Armfield JM, Mohan H, Luzzi L, Chrisopoulos S. Dental anxiety screening practices and self-reported training needs among Australian dentists. Aust Dent J. 2014;59(4):464-72.

24. Hägglin C, Boman UW. A dental phobia treatment within the Swedish National Health Insurance. Swed Dent J. 2012;36(2):71-8. 